\title{
Quality of life of cardiac outpatients with and without psychiatric disorders: a cross-sectional study
}

\author{
Ahmad Alzahrani ${ }^{1,2,3^{*}} \mathbb{D}$, Abdullah Alqahtani ${ }^{1}$, Abeer Saleh ${ }^{4}$, Maryam Aloqalaa ${ }^{5}$, Abdulaziz Abdulmajeed ${ }^{6}$, \\ Asrar Nadhrah ${ }^{7}$ and Nada Alhazmi ${ }^{5}$
}

\begin{abstract}
Background: The study aims to measure the quality of life (QOL) for cardiac outpatients with psychiatric disorders (CPP) in comparison to cardiac outpatients without psychiatric disorders (CPOP). A semi-structured interview was performed for consecutive cardiac outpatients. Psychiatric diagnoses were confirmed using the mini-international neuropsychiatric interview (MINI). The QOL was measured by the World Health Organization quality of life (WHOQOL-BREF).
\end{abstract}

Results: Out of the 343 enrolled patients, 93 (27.1\%) patients were found to have psychiatric disorders. The WHOBREF score of QOL was $4.25 \pm 0.85$. The CPP were found to have statistically significant lower scores in QOL than CPOP in all the WHOQOL-BREF domains. Particularly, the domain of psychological health showed the highest difference between the two groups (76.9 vs. 87.8, $P<0.001$ ), whereas the environment domain showed the lowest difference between them ( 80.2 vs. 87.9, $P<0.001)$. Within each QOL domain, patients with congestive heart failure and psychiatric disorders showed the lowest QOL in both the physical domain (51.4 vs. 71.3, $P<0.02$ ) and the social domain (64.7 vs. 81.9, $P<0.05)$, while patients with vulvular heart disease and psychiatric disorders showed the lowest QOL in the psychological domain (74.6 vs. 85.7, $P<0.001)$ and patients with arrhythmias and psychiatric disorders in the environment domain (80 vs. 86.2, $P<0.02$ ).

Conclusions: The QOL of CPP were found to have poorer QOL than CPOP. The magnitude of difference in QOL was the highest in the psychological health domain and the lowest in the environment domain.

Keywords: Quality of life, Psychiatric disorder, Mental, Cardiovascular disease, Heart, Saudi Arabia, Middle East

\section{Background}

Particularly for chronic diseases, the current practice of medicine has been shifted from symptom-specific treatment, when the treatment is directed to improve distressing symptoms, toward holistic patient-centered care that targets optimizing quality of life and functioning $[1,2]$. For cardiac diseases, although treating symptoms such as shortness of breath, lower limb edema, and palpitation

\footnotetext{
*Correspondence: dr_ahmadsz@yahoo.com

${ }^{2}$ Neuroscience Department, King Faisal Specialist Hospital and Research Center, Jeddah 23433, Saudi Arabia

Full list of author information is available at the end of the article
}

would indicate an improvement in the cardiac disease, a more holistic approach driven by quality-of-life (QOL) measures has been advocated for providing better overall cardiac care [3]. Nonetheless, the QOL of cardiac patients has been found to be consistently lower than the QOL of the general population [4-6]. In a recent systematic review for congestive heart failure (CHF) patients [7], QOL was found to be moderate-to-poor based on both general and specific QOL tools. Similarly, in another systematic review [8], patients with atrial fibrillation (AF) had impaired QOL. 
Given the impact of cardiac diseases on the QOL, including increased mortality, morbidity, difficulties returning to work, and performing daily tasks $[9,10]$, there has been a focus on studying the determinants of the QOL of cardiac patients $[9,11,12]$. Several factors were associated with poor QOL in cardiac patients. Studies found that the severity of the cardiac disease, the comorbidity of other medical conditions, and the psychological state of patients (e.g., depression and anxiety) impact the QOL [12]. The psychological factors were found to independently affect the QOL, especially for depression [13-15]. Not only does depression worsen the QOL of cardiac patients, but it was also found to be associated with worsened clinical outcomes for patients who had cardiac interventions [13, 16]. High levels of anxiety were also associated with poor QOL in patients with cardiac disease [17-19]. Other psychiatric manifestations, such as panic attacks and traumatic experiences, were also found to be associated with poor cardiac outcomes and QOL in patients with heart disease [4, 20, 21].

Psychiatric disorders are common in cardiac patients $[22,23]$. In the current study [23], we found $27.1 \%$ of cardiac outpatients have psychiatric disorders. This is at least two to three times more common than the prevalence of psychiatric disorders in the general population [24-26]. Nonetheless, few have examined the association of psychiatric conditions and the QOL in cardiac patients. While there have been a large number of studies examining particular psychological symptoms with cardiac outcomes and QOL, there is a lack of studies that investigate cardiac patients with established psychiatric diagnoses. Therefore, the aim of the current study was to investigate the QOL of cardiac patients with and without psychiatric disorders using a validated diagnostic method.

\section{Methods}

\section{Study design, setting, and participants}

Through a cross-sectional study design, the study was conducted from July 2017 until January 2018. Participants were recruited from the Cardiology Outpatient Department of King Abdullah Medical City (KAMC). At the time of the study, the hospital delivered tertiary healthcare to residents in Saudi Arabia, mainly for those living on the western coast of the country. Cardiac outpatients who were aged 18 years or older and consented to participate were included in the study. Those with moderate to severe neurocognitive impairment such as dementia and intellectual disability as well as with a language barrier were excluded. The Institutional Review Board of KAMC approved the study.

\section{Recruitment procedure}

Based on the cardiac outpatient list, one of the coauthors approached patients consecutively stratified by gender. The patients were asked if they would like to be part of a study that would include an interview about psychiatric symptoms and demographic background. The consenting process included informing the patient about the possibility of revealing a psychiatric diagnosis upon completing the interview and that they could either contact one of the psychiatrists in the research team or book an appointment at the Mental Health Clinic. The consent process and the interview were carried out in a private clinic room just before the cardiac clinic appointment or immediately after it. Patients' medical records were also reviewed to complete the remaining clinical data.

\section{Psychiatric assessment}

A validated Arabic version of the Mini International Neuropsychiatric Interview 6 (MINI) [27] was used for psychiatric diagnoses. The MINI is a diagnostic tool based on the major Axis I psychiatric diagnoses in the Diagnostic and Statistical Manual of Mental Disorders, 4th Edition, Text Revision (DSM-IV-TR) and the 10th revision of the International Statistical Classification of Diseases and Related Health Problems (ICD-10). It can diagnose 17 common disorders for their current episodes except for major depressive episodes, manic episodes, and hypomanic episodes, where past episodes are explored as well. Besides the MINI, demographic characteristics and clinical data were recorded using a questionnaire in a semi-structured interview. Both the first and the second authors, psychosomatic medicine psychiatrists, trained the other co-authors on how to interview participants using the MINI. A final step was to review all diagnoses by the first and second authors.

\section{Quality-of-life questionnaire}

We used an Arabic version of the abbreviated version of the World Health Organization quality of life (WHOQOL-BREF) [28]. The WHOQOL-BREF is the short version of the WHOQOL 100 items [29] composed of 26 self-administered questions. Participants can respond to the questionnaire items using the 5-point Likert scale, ranging from 1 (very dissatisfied) to 5 (very satisfied). The instrument examines four domains and a general health facet. Within each domain, there are several question items: seven items for physical health, six items for psychological health, three times for social relations, and eight items for the environment domain. The general health facet has two questions; one concerns the subjective satisfaction regarding health, and the second one concerns the overall QOL satisfaction. Each domain 
score is scaled positively (i.e., the higher the score, the higher the QOL). Mean scores are multiplied by 4 to match scores used in the original WHOQOL-100. The range of this conversion is between 4 and 20 . Then, a second conversion is done to range the scores from 0 to 100 .

While cardiac-specific QOL tools are focused on cardiac-specific factors related to QOL, generic QOL, such as the WHOQOL-BREF, can provide a more holistic picture of cardiac patients in regards to their QOL [30, 31]. In addition, although there are specific QOL for cardiac patients, we did not find a validated Arabic version of cardiac-specific QOL instruments. Among diverse clinical conditions, including heart transplants, diabetes, stroke, etc., the WHOQOL-BREF was found to be a reliable, patient-centered instrument [32]. The validated Arabic instrument by Jude U. Ohaeria and Abdel W. Awadalla was used [33]. Their validated instrument was tested in an Arab population sample in Kuwait and found to have acceptable psychometric properties. Another psychometric study in Jordan has shown that the Arabic version of WHOQOL-BREF is a valid instrument [34]. Although their validation studies showed high validity and reliability indices, they were not examined among patients with cardiac diseases or with physical health problems. Hence, we assessed the reliability and validity of the questionnaire among the research participants.

\section{Statistical analysis}

SPSS version 21 was used to perform all statistical analyses. Cardiac patients were grouped by whether they had psychiatric disorders or not. For statistical differences between groups, independent $t$ tests, Chi-square tests, or Fisher's exact tests were used according to the data type. Sociodemographic and clinical characteristics were presented using mean \pm standard deviation (SD) and percentages. All statistical measures were set at a significant level of $\alpha=0.05$.

When measuring the psychometric properties of the WHOQOL, we assessed the internal consistency for the questionnaire, item internal consistency (IIC), item discriminant validity (IDV), and construct validity. These methods have been found suitable and have been reported in previous studies [33, 34]. We calculated the Cronbach's alpha coefficients to ascertain the internal consistency reliability. For IIC and IDV, we used Pearson correlations; for construct validity, we used a principal component analysis (PCA). For the factor analysis, the suitability of the questionnaire was assessed using the Kaiser-Meyer-Oklin (KMO) test and Bartlett's test of sphericity. Then, the number of components was determined by reviewing the total variance and the number of eigenvalues of each component. Components greater than 1 were considered to represent one construct dimension (theme). Similar to previous studies, we used the suggested orthogonal rotation for factor extraction when eigenvalues are greater than 1 , since different rotations were found to lead to similar results [35].

\section{Results}

The psychometric properties of the WHOQOL-BREF

For reliability, the Cronbach alpha of the WHOQOLBREF was found to be 0.89 , indicating very good internal consistency reliability. The corrected item-total correlations between each item in the questionnaire ranged from 0.36 to 0.65 if we excluded the question item 4, "How much do you need any medical treatment to function in your daily life?" which was - 0.004. Regarding exploratory factor analysis, Bartlett's test of sphericity was statistically significant $(P<0.001)$, suggesting the factorizability of the data. In addition, the KMO was 0.891 , indicating meritorious suitability, according to Kaiser [36]. Based on a minimum eigenvalue of 1.0, five factors were extracted, accounting for $52.2 \%$ of the variance. Communalities were acceptable, ranging from 0.33 to 0.73 . Table 1 shows the items ordered by size of loading. The five components are conceptually similar to the WHOQOL-BREF in regard to covering the physical, psychological, social, and environmental needs. Similar to Dalky, Heyam et al.s [34] first four components were strong, and the weakest was the last one, which has only one negatively worded item in our study (Table 1).

\section{Sample characteristics}

Out of the 346 approached outpatients, 343 were recruited (Table 2). Five patients were excluded because of a refusal to participate or conflicting appointments. The age of the participants ranged from 18 to 90 years $(55.54 \pm 13.83)$. Psychiatric disorders were found in 93 (27.1\%) patients. Those patients with at least one psychiatric disorder were significantly different from the patients without any psychiatric disorder in regard to age (mean; 52.65 vs. $56.62, P<0.018$ ) and marital status $(P<0.036)$. While no significant differences existed in the medical background between the two groups, cardiac patients with psychiatric disorders reported current cigarette smoking more than cardiac patients without psychiatric disorders ( $23.7 \%$ vs. $11.3 \%, P<0.004)$.

Regarding cardiac diseases, coronary artery disease was found in 228 patients, valvular heart disease (VHD) in 82 patients, congestive heart failure (CHF) in 51 patients, arrhythmias in 85 patients, and other cardiac conditions in 10 patients. Patients with other cardiac conditions include eight patients with congenital heart diseases, one patient with an atrioventricular septal defect, and one patient with Marfan syndrome. 
Table 1 Item loading for the factor analysis of the 26 items of the WHOQOL-BREF

\begin{tabular}{|c|c|c|c|}
\hline Factor label & Item loading & Eigenvalue & $\%$ Variance \\
\hline \multicolumn{4}{|l|}{ Factor 1: general health and overall QOL } \\
\hline 1) \# Satisfied with overall OOL & 0.653 & 7.75 & 29.8 \\
\hline 2) \# Satisfied with the general health & 0.505 & & \\
\hline 7) \# able to concentrate & 0.501 & & \\
\hline 8) \# feel safe in daily life & 0.598 & & \\
\hline 9) healthy physical environment & 0.469 & & \\
\hline 11) satisfied with bodily appearance & 0.583 & & \\
\hline 19) satisfied with self & 0.646 & & \\
\hline 20) satisfied with personal relationship & 0.524 & & \\
\hline 26) having negative feeling & 0.607 & & \\
\hline \multicolumn{4}{|l|}{ Factor 2: physical health } \\
\hline 3) pain preventing activities & 0.630 & 1.98 & 7.61 \\
\hline 10) having enough energy & 0.643 & & \\
\hline 15) \# able to get around & 0.582 & & \\
\hline 16) satisfied with sleep & 0.550 & & \\
\hline 17) satisfied on performing daily activities & 0.776 & & \\
\hline 18) satisfied with capacity to work & 0.760 & & \\
\hline 21) satisfied with sexual life & 0.401 & & \\
\hline \multicolumn{4}{|l|}{ Factor 3: environment } \\
\hline 12) have enough money for needs & 0.565 & 1.43 & 5.5 \\
\hline 13) satisfied with availability of daily information & 0.589 & & \\
\hline 23) satisfied with living condition & 0.714 & & \\
\hline 24) satisfied with accessibility to health services & 0.458 & & \\
\hline 25) satisfied with transportation & 0.676 & & \\
\hline \multicolumn{4}{|l|}{ Factor 4: psychological health } \\
\hline 5) enjoys life & 0.537 & 1.29 & 4.95 \\
\hline 6) \# feel life meaningful & 0.501 & & \\
\hline 14) opportunity for leisure activities & 0.640 & & \\
\hline 22) satisfied with friends'support & 0.581 & & \\
\hline \multicolumn{4}{|l|}{ Factor 5: treatment } \\
\hline 4) needed treatment to function & -0.772 & 1.12 & 4.32 \\
\hline
\end{tabular}

\section{Prevalence of psychiatric disorders}

Further results and discussion about psychiatric disorders were published elsewhere [23]. Ninety-three (27.1\%) of the recruited participants were found to have at least one psychiatric disorder. A past major depressive disorder (MDD) was found to be the most common disorder accounting for $14 \%$. The other two most common disorders were current generalized anxiety disorder (GAD) and current MDD, accounting for $12.8 \%$ and $8.5 \%$, respectively. Other disorders include panic disorder (4.1\%), agoraphobia $(4.1 \%)$, social phobia $(0.6 \%)$, obsessive-compulsive disorder (OCD) $(0.3 \%)$, post-traumatic stress disorder (PTSD) (2\%), substance abuse (0.6\%), and current psychotic disorder $(0.3 \%)$. Regarding specific cardiac diseases and psychiatric disorders, VHD patients were found to have the highest comorbidity with psychiatric disorders (32.9\%), followed by patients with arrhythmias (30.6\%), CAD (25.4\%), and CHF (19.6\%). History of past and family psychiatric illnesses were reported among 33 patients and 41 patients, respectively.

\section{Quality of life of patients with and without psychiatric disorders}

The WHO-BREF score of QOL for all cardiac patients was $4.25 \pm 0.85$, and $7(1.5 \%)$ had scores below the middle value of 3 . The health assessment score was $4.12 \pm 1.11$, and $36(6.8 \%)$ had scores below the middle value of 3 . Among the WHOQOL-BREF domains, the environment domain had the highest mean score, $85.8 \pm 12.1$, while the physical health had the lowest mean score, $70.6 \pm 16.3$. Table 3 shows the domain scores for the WHOQOL-BREF.

Regarding the QOL for cardiac patients with and without psychiatric disorders, those with psychiatric 
Table 2 Demographics and medical background of cardiac outpatients with different cardiac conditions ( $N=343$ )

\begin{tabular}{|c|c|c|c|c|c|c|}
\hline $\begin{array}{l}\text { Demographic } \\
\text { characteristics }\end{array}$ & $\begin{array}{l}\text { Total sample } \\
(N=343) N \\
(\%)\end{array}$ & CAD $(N=228) N(\%)$ & $\begin{array}{l}\text { Valvular heart } \\
\text { disease }(N=82) \\
N(\%)\end{array}$ & $\begin{array}{l}\text { Congestive heart } \\
\text { failure }(N=51) \\
N(\%)\end{array}$ & $\begin{array}{l}\text { Arrhythmias } \\
(N=85) N \\
(\%)\end{array}$ & Other $(N=10) N(\%)$ \\
\hline Age (Mean $\pm S D)$ & $55.54 \pm 13.83$ & $58.77 \pm 11.25$ & $46.49 \pm 15.02$ & $55.63 \pm 15.47$ & $55.07 \pm 15.33$ & $37.5 \pm 15.32$ \\
\hline \multicolumn{7}{|l|}{ Gender } \\
\hline Male & $173(50.4 \%)$ & $137(60.1 \%)$ & $21(25.6 \%)$ & $31(60.8 \%)$ & $26(30.6 \%)$ & $2(20.0 \%)$ \\
\hline Female & $170(49.6 \%)$ & 91 (39.9\%) & $61(74.4 \%)$ & $20(39.2 \%)$ & $59(69.4 \%)$ & $8(80.0 \%)$ \\
\hline \multicolumn{7}{|l|}{ Marital status } \\
\hline Single & $24(7 \%)$ & $9(3.9 \%)$ & $13(15.9 \%)$ & $7(13.7 \%)$ & $8(9.4 \%)$ & $3(33.3 \%)$ \\
\hline Married & $251(73.4 \%)$ & $172(75.4 \%)$ & 54 (65.9\%) & 37 (72.5\%) & $57(67.1 \%)$ & $5(55.6 \%)$ \\
\hline Widowed & $54(15.8 \%)$ & $38(16.7 \%)$ & $11(13.4 \%)$ & $6(11.8 \%)$ & $16(18.8 \%)$ & $1(11.1 \%)$ \\
\hline Divorced & $13(3.8 \%)$ & $9(3.9 \%)$ & $4(4.9 \%)$ & $1(2.0 \%)$ & $4(4.7 \%)$ & 0 \\
\hline \multicolumn{7}{|l|}{ Education } \\
\hline Illiterate & $95(27.8 \%)$ & $63(27.6 \%)$ & $20(24.4 \%)$ & $11(22.0 \%)$ & $31(36.5 \%)$ & 0 \\
\hline Primary school & 65 (19\%) & 47 (20.6\%) & $15(18.3 \%)$ & $10(20.0 \%)$ & $15(17.6 \%)$ & $1(10.0 \%)$ \\
\hline $\begin{array}{l}\text { Intermediate/Second- } \\
\text { ary }\end{array}$ & $100(29.2 \%)$ & $64(28.1 \%)$ & $28(34.1 \%)$ & 15 (30.0\%) & $26(30.6 \%)$ & $5(50.0 \%)$ \\
\hline Undergraduate & $7(2 \%)$ & $4(1.8 \%)$ & $1(1.2 \%)$ & $1(2.0 \%)$ & $2(2.4 \%)$ & 0 \\
\hline Postgraduate & 75 (21.9\%) & $50(21.9 \%)$ & $18(22.0 \%)$ & $13(26.0 \%)$ & $11(12.9 \%)$ & $4(40.0 \%)$ \\
\hline \multicolumn{7}{|l|}{ Occupation } \\
\hline Yes & $75(22 \%)$ & $55(24.2 \%)$ & $13(15.9 \%)$ & $10(20.4 \%)$ & $12(14.1 \%)$ & $5(50.0 \%)$ \\
\hline No & $266(78 \%)$ & $172(75.8 \%)$ & 69 (84.1\%) & 39 (79.6\%) & 73 (85.9\%) & $5(50.0 \%)$ \\
\hline \multicolumn{7}{|l|}{ Income (SAR)/month } \\
\hline$<5000$ & $165(48.7 \%)$ & $107(47.1 \%)$ & 47 (58.0\%) & $23(46.9 \%)$ & $50(58.8 \%)$ & $3(33.3 \%)$ \\
\hline $5000-10,000$ & 89 (26.3\%) & 65 (28.6\%) & $17(21.0 \%)$ & $9(18.4 \%)$ & $20(23.5 \%)$ & $1(11.1 \%)$ \\
\hline$>10,000$ & $85(25.1 \%)$ & $55(24.2 \%)$ & $17(21.0 \%)$ & $17(34.7 \%)$ & $15(17.6 \%)$ & $5(55.6 \%)$ \\
\hline \multicolumn{7}{|l|}{ Children } \\
\hline Yes & $306(89.7 \%)$ & $211(92.5 \%)$ & $66(80.5 \%)$ & $43(86.0 \%)$ & 75 (88.2\%) & $6(66.7 \%)$ \\
\hline No & $35(10.3 \%)$ & $17(7.5 \%)$ & $16(19.5 \%)$ & 7 (14.0\%) & $10(11.8 \%)$ & $3(33.3 \%)$ \\
\hline \multicolumn{7}{|l|}{ Medical background } \\
\hline Smoking (current) & $50(14.7 \%)$ & $46(20.2 \%)$ & $5(6.1 \%)$ & $2(4.1 \%)$ & $6(7.1 \%)$ & 0 \\
\hline Hypertension & $183(53.4 \%)$ & $141(61.8 \%)$ & $27(32.9 \%)$ & $22(43.1 \%)$ & $38(44.7 \%)$ & $3(30.0 \%)$ \\
\hline Diabetes & $161(46.9 \%)$ & $134(58.8 \%)$ & $17(20.7 \%)$ & $22(43.1 \%)$ & $30(35.3 \%)$ & $2(20.0 \%)$ \\
\hline Dyslipidemia & $183(53.4 \%)$ & $146(64.0 \%)$ & $23(28.0 \%)$ & $22(43.1 \%)$ & 31 (36.5\%) & $3(30.0 \%)$ \\
\hline CKD & $10(2.9 \%)$ & $7(3.1 \%)$ & $2(2.4 \%)$ & $2(3.9 \%)$ & $2(2.4 \%)$ & 0 \\
\hline Other & $32(9.3 \%)$ & $22(9.7 \%)$ & $11(13.4 \%)$ & $4(7.8 \%)$ & $5(5.9 \%)$ & $1(10.0 \%)$ \\
\hline Past psychiatric history & $33(9.6 \%)$ & $22(9.7 \%)$ & $8(9.8 \%)$ & $7(13.7 \%)$ & $10(11.8 \%)$ & $3(30 \%)$ \\
\hline Personal family & $41(12 \%)$ & $27(11.8 \%)$ & $8(9.8 \%)$ & $4(7.8 \%)$ & $11(12.9 \%)$ & $1(10 \%)$ \\
\hline
\end{tabular}

Table 3 Quality of life for cardiac outpatients with and without psychiatric disorders

\begin{tabular}{|c|c|c|c|c|c|}
\hline & Total $(N=343)$ & $\begin{array}{l}\text { With psychiatric disorder } \\
(N=93)\end{array}$ & $\begin{array}{l}\text { Without psychiatric } \\
\text { disorder } \\
(N=246)\end{array}$ & $t$ test & $P *$ \\
\hline Overall QoL & $4.25 \pm 0.85$ & $3.99 \pm 0.93$ & $4.35 \pm 0.8$ & 3.53 & $<0.001$ \\
\hline Health assessment & $4.12 \pm 1.11$ & $3.76 \pm 1.35$ & $4.25 \pm 0.96$ & 3.18 & $<0.001$ \\
\hline Physical health & $70.6 \pm 16.3$ & $63.6 \pm 17$ & $73.4 \pm 15.2$ & 5.11 & $<0.001$ \\
\hline Psychological & $84.8 \pm 13.5$ & $76.9 \pm 16.2$ & $87.8 \pm 10.9$ & 5.99 & $<0.001$ \\
\hline Social relationships & $81.4 \pm 16$ & $75.3 \pm 19.2$ & $83.6 \pm 14$ & 3.79 & $<0.001$ \\
\hline Environment & $85.8 \pm 12.1$ & $80.2 \pm 13.9$ & $87.9 \pm 10.7$ & 4.85 & $<0.001$ \\
\hline
\end{tabular}

*Independent sample $t$ test was used between cardiac patients with psychiatric disorders vs. cardiac patients without psychiatric disorders 
disorders had statistically significantly lower scores in QOL than those without psychiatric disorders in all the WHOQOL-BREF domains. Particularly, the domain of psychological health showed the highest difference between the two groups ( 76.9 vs. $87.8, P<0.001)$, whereas the environment domain showed the lowest difference between them (80.2 vs. 87.9, $P<0.001)$.

Within each QOL domain, patients with CHF and psychiatric disorders showed the lowest QOL in both the physical domain $(51.4$ vs. $71.3, P<0.02)$ and the social domain (64.7 vs. 81.9, $P<0.05)$, while patients with VHD and psychiatric disorders showed the lowest QOL in the psychological domain $(74.6$ vs. $85.7, P<0.001)$ and patients with arrhythmias and psychiatric disorders in the environment domain ( 80 vs. $86.2, P<0.02$ ). Figure 1 shows the chart bar for the differences between cardiac patients with and without psychiatric disorders for each domain.

\section{Discussion}

We found a large number of cardiac patients with psychiatric disorders (27.1\%). As stated earlier, psychiatric disorders are common in the general population; however, the percentage of psychiatric disorders in cardiac patients in the current study outnumbered the general population by two to three times. This is in line with the findings that psychiatric disorders are more common in other medical conditions in comparison to the psychiatric disorders in the general population [24-26]. Multiple factors were postulated in the commonality of mental conditions in the medical conditions, including inflammatory processes, pharmacological side effects, psychological factors, and social impact [37-39]. Further details about the prevalence of psychiatric disorders in our sample were published elsewhere [23].

Despite heart conditions significantly impacting QOL, other factors play an important role as well, including age, sex, medical comorbidities, body mass index, smoking status, social support, depression, and anxiety $[9,18]$. In the current study, all the WHOQOL domains were found to be poorer for cardiac patients with psychiatric disorders than those without psychiatric disorders, particularly for the psychological health domain. Studies found that cardiac patients have poorer QOL and healthrelated QOL (HRQOL) than healthy controls, and those who were untreated were found to have even poorer HRQOL than treated patients $[9,11]$. For the psychological impact, Michael Weiss et al. [18] found that depression, anxiety, and poor social support affected HRQOL negatively in patients with CAD. Similarly, in patients with CHF, depression was found to independently predict worsening of QOL, heart failure symptoms, and physical and social functioning [40]. For patients with arrhythmia, although the number of shocks was significantly correlated with worsening QOL [41], depression, trait anxiety, and perceived social support accounted for $25-40 \%$ of the QOL variance more than the number of shocks, which accounted for only 1-7\% [42].

As pointed earlier, all WHOQOL domains showed significant differences between those with and without psychiatric disorders, but the largest difference was for the psychological health domain and the lowest for the environmental domain. Given the relationship of the psychological health domain with psychiatric disorders, this

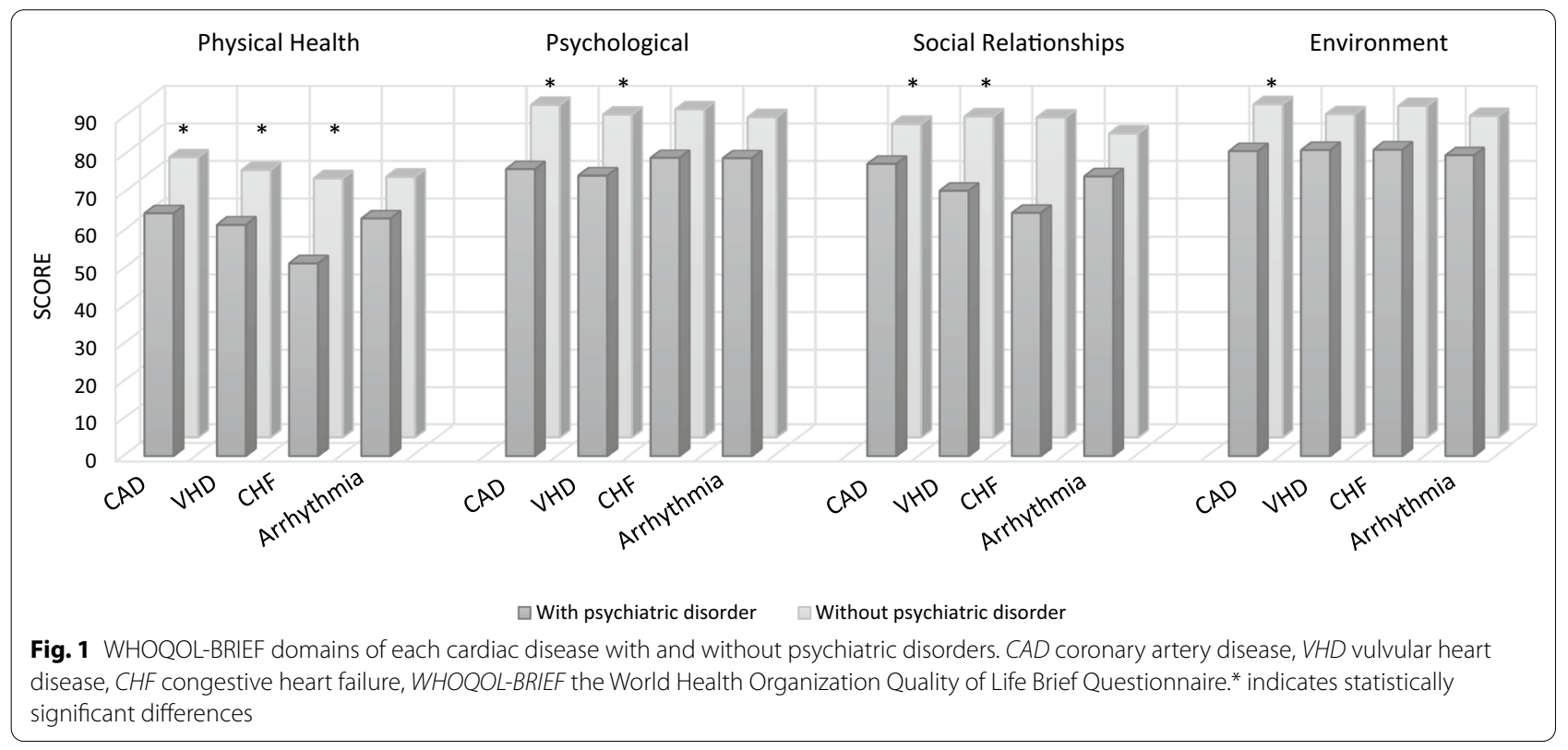


could explain the high difference between the two groups in this particular domain. Among 123 cardiac patients, depressive symptoms were significantly associated with QOL at enrollment and later at 6 weeks [18]. For the environmental domain, which assesses the financial, transportation, living place, and leisure activities, the differences were perceived slightly but significantly between cardiac patients with and without psychiatric disorders. One study found that the environmental domain was the best-rated domain among the other domains of the WHOQOL [43].

The current study has several strengths. First, it used a generic validated scale, the WHOQOL-BREF, to assess the quality of life. Second, the sample size was adequately addressed, although choosing a better probability sampling method would be a better option for representing the recruited sample. Third, psychiatric disorders were assessed using a validated diagnostic tool instead of a screening instrument. Regarding study limitations, although the study is descriptive in nature, it did not account for the onset, duration, and severity of the cardiac conditions, which could have a significant impact on the QOL. This did not allow us to be able to examine the association of the QOL and other factors. In addition, the study recruited patients from one single tertiary hospital, and, as noted above, the sampling method used a non-probability sampling method; thus, generalization to other cardiac populations should be sought with caution.

\section{Conclusions}

The current study found a significantly lower QOL in all the domains of the WHOQOL-BREF among cardiac patients with psychiatric disorders in comparison to those without psychiatric disorders. Given the relationship of the psychological domain with psychiatric disorders, the psychological domain of the WHOQOL-BREF showed the highest difference between cardiac patients with and without psychiatric disorders. The environment domain showed the best score among the other domains for all the cardiac patients and also the lowest difference between cardiac patients with and without psychiatric conditions. For each QOL domain, both the physical and social domains were the lowest in patients with CHF and psychiatric disorders, while the psychological domain was lowest in patients with VHD and psychiatric disorders. The environment domain was found to be lowest among patients with arrhythmias and psychiatric conditions. Since psychiatric disorders are associated with significant comorbidity and mortality for cardiac patients, proactive assessment and intervention are recommended in the holistic management guidelines for such patients.

\section{Abbreviations}

AF: Atrial fibrillation; CHF: Congestive heart failure; CPOP: Cardiac outpatients without psychiatric disorders; CPP: Cardiac outpatients with psychiatric disorders; DSM-IV-TR: The Diagnostic and Statistical Manual of Mental Disorders, 4th Edition, Text Revision; GAD: Generalized anxiety disorder; ICD-10: The 10th revision of the International Statistical Classification of Diseases and Related Health Problems; IDV: Item discriminant validity; IIC: Item internal consistency; KMO: The Kaiser-Meyer-Oklin; MDD: Major depressive disorder; MINI: The mini-international neuropsychiatric interview; PCA: Principal component analysis; QOL: Quality of life; WHOQOL-BREF: The World Health Organization quality of life; VHD: Valvular heart disease.

\section{Acknowledgements \\ Not applicable.}

\section{Authors' contributions}

All authors contributed to the study conception and design. Material preparation, data collection and analysis were performed by all authors. The first draft of the manuscript was written by $A Z$ and all authors commented on previous versions of the manuscript. All authors read and approved the final manuscript.

\section{Funding}

No source of funding for the study.

Availability of data and materials

Study data are not available.

\section{Declarations}

Ethics approval and consent to participate

This study was approved by the ethics committee of King Abdullah Medical City with approval number 17-372. The patients provided written consent.

\section{Consent for publication}

Not applicable.

\section{Competing interests}

The authors have no financial or proprietary interests in any material discussed in this article.

\section{Author details}

${ }^{1}$ Mental Health Department, Neuroscience Center, King Abdullah Medical City, Makkah, Saudi Arabia. ${ }^{2}$ Neuroscience Department, King Faisal Specialist Hospital and Research Center, Jeddah 23433, Saudi Arabia. ${ }^{3}$ College of Medicine, Alfaisal University, Riyadh, Saudi Arabia. ${ }^{4}$ Family Medicine, Department of Family Medicine, Ministry of Health, Riyadh, Saudi Arabia. ${ }^{5}$ Emergency Medicine, Department of Emergency Medicine, King Abdulaziz Medical City, Riyadh, Saudi Arabia. ${ }^{6}$ Department of Urology, King Fahad Hospital, Jeddah, Saudi Arabia. ${ }^{7}$ Family Medicine, Department of Family Medicine, King Fahad Medical City, Riyadh, Saudi Arabia.

Received: 5 May 2021 Accepted: 30 December 2021

Published online: 20 January 2022

\section{References}

1. Cramm JM, Nieboer AP. Is "disease management" the answer to our problems? No! Population health management and (disease) prevention require "management of overall well-being." BMC Health Serv Res. 2016;16(1):500.

2. Kuipers SJ, Cramm JM, Nieboer AP. The importance of patient-centered care and co-creation of care for satisfaction with care and physical and social well-being of patients with multi-morbidity in the primary care setting. BMC Health Serv Res. 2019;19(1):13.

3. Faxon DP, Schwamm LH, Pasternak RC, Peterson ED, McNeil BJ, Bufalino V, et al. Improving quality of care through disease management: principles and recommendations from the American Heart Association's Expert Panel on Disease Management. Circulation. 2004;109(21):2651-4. 
4. Srivastava S, Shekhar S, Bhatia MS, Dwivedi S. Quality of life in patients with coronary artery disease and panic disorder: a comparative study. Oman Med J. 2017;32(1):20-6.

5. Seo J, Lee Y, Kang S, Chun H, Pyun WB, Park SH, et al. Poor health-related quality of life and proactive primary control strategy may act as risk factors for acute coronary syndrome. Korean Circ J. 2015;45(2):117-24.

6. Unsar S, Sut N, Durna Z. Health-related quality of life in patients with coronary artery disease. J Cardiovasc Nurs. 2007;22(6):501-7.

7. Moradi M, Daneshi F, Behzadmehr R, Rafiemanesh H, Bouya S, Raeisi M. Quality of life of chronic heart failure patients: a systematic review and meta-analysis. Heart Fail Rev. 2020;25(6):993-1006.

8. Thrall G, Lane D, Carroll D, Lip GY. Quality of life in patients with atrial fibrillation: a systematic review. Am J Med. 2006;1 19(5):448.

9. Sajobi TT, Wang M, Awosoga O, Santana M, Southern D, Liang Z, et al. Trajectories of health-related quality of life in coronary artery disease. Circulation. 2018;11(3):e003661.

10. Elliott VJ, Rodgers DL, Brett SJ. Systematic review of quality of life and other patient-centred outcomes after cardiac arrest survival. Resuscitation. 2011;82(3):247-56.

11. Roy B, Wolf JR, Carlson MD, Akkermans R, Bart B, Batalden P, et al. An international comparison of factors affecting quality of life among patients with congestive heart failure: a cross-sectional study. PLOS ONE. 2020;15(4):e0231346

12. Baert A, De Smedt D, De Sutter J, De Bacquer D, Puddu PE, Clays E, et al. Factors associated with health-related quality of life in stable ambulatory congestive heart failure patients: systematic review. Eur J Prev Cardiol. 2018:25(5):472-81.

13. Hare DL, Toukhsati SR, Johansson P, Jaarsma T. Depression and cardiovascular disease: a clinical review. Eur Heart J. 2013;35(21):1365-72.

14. Baumeister H, Hutter N, Bengel J, Härter M. Quality of life in medically III persons with comorbid mental disorders. A systematic review and metaanalysis. Psychother Psychosomatics. 2011;80(5):275-86.

15. Bahall M, Legall G, Khan K. Quality of life among patients with cardiac disease: the impact of comorbid depression. Health Qual Life Outcomes. 2020;18(1):189.

16. Zhang WY, Nan N, Song XT, Tian JF, Yang XY. Impact of depression on clinical outcomes following percutaneous coronary intervention: a systematic review and meta-analysis. BMJ Open. 2019;9(8):e026445.

17. AbuRuz ME. Anxiety and depression predicted quality of life among patients with heart failure. J Multidiscip Healthc. 2018;11:367-73.

18. Weiss M, Michels G, Eberhardt F, Fehske W, Winter S, Baer F, et al. Anxiety, depression and quality of life in acute high risk cardiac disease patients eligible for wearable cardioverter defibrillator: results from the prospective multicenter CRED-registry. PLoS ONE. 2019;14(3):e0213261.

19. Allabadi H, Alkaiyat A, Alkhayyat A, Hammoudi A, Odeh H, Shtayeh J, et al. Depression and anxiety symptoms in cardiac patients: a cross-sectional hospital-based study in a Palestinian population. BMC Public Health 2019;19(1):232.

20. Cohen BE, Marmar CR, Neylan TC, Schiller NB, Ali S, Whooley MA. Posttraumatic stress disorder and health-related quality of life in patients with coronary heart disease: findings from the Heart and Soul Study. Arch Gen Psychiatry. 2009;66(11):1214-20.

21. Sowden GL, Huffman JC. The impact of mental illness on cardiac outcomes: a review for the cardiologist. Int J Cardiol. 2009;132(1):30-7.

22. Ormel J, Von Korff M, Burger H, Scott K, Demyttenaere K, Huang YQ, et al. Mental disorders among persons with heart disease - results from World Mental Health surveys. Gen Hosp Psychiatry. 2007;29(4):325-34.

23. Alzahrani AS, Alqahtani A, Saleh A, Aloqalaa M, Abdulmajeed A, Nadhrah $A$, et al. Prevalence of psychiatric disorders in cardiac outpatients. Psychiatr Ann. 2020;50(9):403-15.

24. Roca M, Gili M, Garcia-Garcia M, Salva J, Vives M, Garcia Campayo J, et al. Prevalence and comorbidity of common mental disorders in primary care. J Affect Disord. 2009;119(1):52-8.

25. Rothenhäusler HB. Mental disorders in general hospital patients. Psychiatr Danub. 2006;18(3-4):183-92.

26. Demyttenaere K, Bruffaerts R, Posada-Villa J, Gasquet I, Kovess V, Lepine $J P$, et al. Prevalence, severity, and unmet need for treatment of mental disorders in the World Health Organization World Mental Health Surveys. JAMA. 2004;291(21):2581-90.

27. Kadri N, Agoub M, El Gnaoui S, Alami KhM, Hergueta T, Moussaoui D. Moroccan colloquial Arabic version of the Mini International
Neuropsychiatric Interview (MINI): qualitative and quantitative validation. Eur Psychiatry. 2005;20(2):193-5

28. Group W. Development of the World Health Organization WHOQOL-BREF quality of life assessment. Psychol Med. 1998;28(3):551-8

29. Group TW. The World Health Organization quality of life assessment (WHOQOL): development and general psychometric properties. Soc Sci Med. 1998;46(12):1569-85.

30. Gierlaszyńska K, Pudlo R, Jaworska I, Byrczek-Godula K, Gąsior M. Tools for assessing quality of life in cardiology and cardiac surgery. Kardiochir Torakochirurgia Pol. 2016;13(1):78-82.

31. Haraldstad K, Wahl A, Andenæs R, Andersen JR, Andersen MH, Beisland $E$, et al. A systematic review of quality of life research in medicine and health sciences. Qual Life Res. 2019;28(10):2641-50.

32. Skevington SM, McCrate FM. Expecting a good quality of life in health: assessing people with diverse diseases and conditions using the WHOQOL-BREF. Health Expect. 2012;15(1):49-62.

33. Ohaeri JU, Awadalla AW. The reliability and validity of the short version of the WHO Quality of Life Instrument in an Arab general population. Ann Saudi Med. 2009;29(2):98-104.

34. Dalky HF, Meininger JC, Al-Ali NM. The reliability and validity of the Arabic World Health Organization quality of life-BREF instrument among family caregivers of relatives with psychiatric illnesses in Jordan. J Nurs Res. 2017;25(3):224-30

35. Polit DF. Statistics and data analysis for nursing research. 2nd ed. Upper Saddle River: Pearson; 2010

36. Kaiser HF. An index of factorial simplicity. Psychometrika. 1974;39(1):31-6.

37. Mensah GA, Collins PY. Understanding mental health for the prevention and control of cardiovascular diseases. Glob Heart. 2015;10(3):221-4.

38. Alosaimi F, Hawa R. Broken heart: broken mind. J Psychosom Res. 2009;67(4):285-7

39. Abed MA, Kloub MI, Moser DK. Anxiety and adverse health outcomes among cardiac patients: a biobehavioral model. J Cardiovasc Nurs. 2014:29(4):354-63.

40. Rumsfeld JS, Havranek E, Masoudi FA, Peterson ED, Jones P, Tooley JF, et al. Depressive symptoms are the strongest predictors of short-term declines in health status in patients with heart failure. J Am Coll Cardiol. 2003;42(10):1811-7.

41. Jacq F, Foulldrin G, Savouré A, Anselme F, Baguelin-Pinaud A, Cribier A et al. A comparison of anxiety, depression and quality of life between device shock and nonshock groups in implantable cardioverter defibrillator recipients. Gen Hosp Psychiatry. 2009;31(3):266-73.

42. Sears SF, Lewis TS, Kuhl EA, Conti JB. Predictors of quality of life in patients with implantable cardioverter defibrillators. Psychosomatics. 2005:46(5):451-7.

43. Komalasari R, Nurjanah MMY. Quality of life of people with cardiovascular disease: a descriptive study. Asian/Pac Island Nurs J. 2019:4(2):92.

\section{Publisher's Note}

Springer Nature remains neutral with regard to jurisdictional claims in published maps and institutional affiliations.

\section{Submit your manuscript to a SpringerOpen ${ }^{\circ}$ journal and benefit from:}

- Convenient online submission

- Rigorous peer review

- Open access: articles freely available online

- High visibility within the field

Retaining the copyright to your article

Submit your next manuscript at springeropen.com 